ROVARIS, E. et al. Desempenho de frangos de corte criados em aviários dark house versus convencional. PUBVET, Londrina, V. 8, N. 18, Ed. 267, Art. 1778, Setembro, 2014.

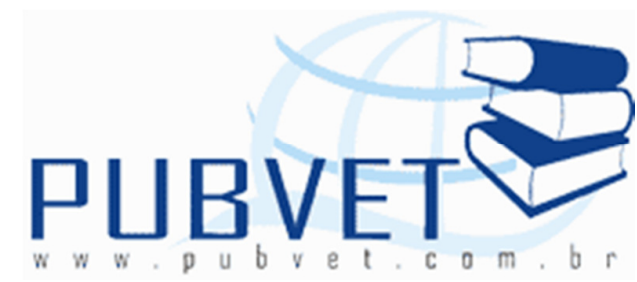

PUBVET, Publicações em Medicina Veterinária e Zootecnia.

\title{
Desempenho de frangos de corte criados em aviários dark house versus convencional
}

\section{Ellen Rovaris ${ }^{1}$, Gerusa da Silva Salles Corrêa ${ }^{2}$, André Brito Corrêa ${ }^{2}$, João Garcia Caramori Junior ${ }^{2}$, Uanderson Verrissímo de Luna ${ }^{1}$, Saullo Diogo de Assis ${ }^{1}$}

Mestrandos do programa de pós-graduação em Ciência Animal, Universidade Federal de mato grosso, UFMT, Cuiabá, MT. E-mail: ellenrovaris@hotmail.com. ${ }^{2}$ Profs. Drs. Adjuntos Dept $^{\circ}$ de Ciências Básicas e Produção Animal, FAMEV/ UFMT, Cuiabá, MT.

\section{Resumo}

Com o objetivo de avaliar o desempenho zootécnico de frangos de corte em duas diferentes instalações, aviários convencionais (com ventilação positiva) e aviários dark house (com ventilação negativa e cortina escura), foi realizado este estudo, a partir de dados de campo de uma empresa avícola situada em região com clima quente em MT. Foram avaliados os desempenhos dos frangos de corte através do peso corporal, ganho de peso, consumo alimentar, conversão alimentar, mortalidade e incidência de calos de pata. Os resultados mostraram que os frangos criados em galpões no sistema dark house apresentaram melhores desempenhos para peso final, ganho de peso, consumo alimentar e conversão alimentar. Houve redução significativa na incidência de calos de patas dos frangos criados em galpões de sistema convencional Quanto à mortalidade durante a criação não houve diferença 
ROVARIS, E. et al. Desempenho de frangos de corte criados em aviários dark house versus convencional. PUBVET, Londrina, V. 8, N. 18, Ed. 267, Art. 1778, Setembro, 2014.

significativa entre as duas tecnologias. Assim o melhor sistema em relação aos resultados zootécnicos para a criação de frangos em região quente é o sistema dark house.

Palavras-chave: aves, clima quente, frangos de corte,peso corporal, produtividade, sistema de criação.

\title{
Performance of broiler chickens createdin aviaries dark house versus conventional
}

\begin{abstract}
In order to evaluate the growth performance of broiler chickens at two different facilities, conventional aviaries (with positive ventilation) and avian dark house (with negative ventilation dark curtain), this study was conducted, from data field of a poultry company located in a region with a warm climate in state of Mato Grosso, Brazil. Was evaluated the performance of broilers by body weight, weight gain, feed intake, feed conversion, mortality and incidence of foot calluses. The results showed that broilers reared in dark house sheds system presented better performances for final weight, weight gain, feed intake and feed conversion. Significant reduction in the incidence of foot callus of chickens reared in conventional sheds. Regarding mortality while creating, there was no significant difference between the two technologies. So the best system, regarding zootechnical results for the keeping of chickens in hot region is the dark house system.
\end{abstract} Keywords: poultry, hot weather, broiler body weight, productivity, system creation.

\section{Introdução}

O melhoramento genético dos frangos de corte nos últimos anos proporcionou frangos com ganho de peso mais rápido, alto rendimento de carcaça, alta eficiência alimentar, entre outros. Porém manter o desempenho 
ROVARIS, E. et al. Desempenho de frangos de corte criados em aviários dark house versus convencional. PUBVET, Londrina, V. 8, N. 18, Ed. 267, Art. 1778, Setembro, 2014.

no sistema de criação convencional principalmente em clima quente tem sido o maior desafio na produção.

Os frangos de corte necessitam serem mantidos na zona de termoneutralidade, para evitar o desperdício de energia na manutenção da temperatura corporal. Desta forma, que quando são pintinhos, a temperatura deve ficar em torno $33^{\circ} \mathrm{C}$ a $34^{\circ} \mathrm{C}$ e quando são adultos precisam ser mantidos entre $15^{\circ} \mathrm{C}$ a $28^{\circ} \mathrm{C}$ com umidade variando de 40 a $80 \%$. Além desses parâmetros é ideal que o ar dentro das instalações seja de boa qualidade. (WELKER et al., 2008).

Segundo Nazareno et al. (2009) a zona de termoneutralidade está relacionada a um ambiente térmico ideal no qual as aves encontram condições adequadas para expressar suas melhores características produtivas. Para manter as aves dento desta zona de conforto térmico muitos fatores são importantes, desde a disposição dos aviários, arborização, ventilação, que pode ser natural ou artificial.

O sistema de ventilação, com o uso de ventiladores também chamado de ventilação positiva associada à nebulização e manejo de cortinas é um sistema que visa manter as aves nesta zona de termoneutralidade, assim também como os aviários equipados com exaustores (ventilação negativa) associados à nebulizadores ou a placas evaporativas também visam criar as aves dentro de condições térmicas ideais para o desenvolvimento e melhor produtividade.

Conforme Tinôco (2004) o sistema de ventilação por pressão negativa o ar é succionado por exaustores de dentro para fora, criando um vácuo parcial no interior da construção; desse modo, succionando o ar externo, já no sistema de ventilação com pressão positiva o ar externo é forçado, por meio de ventiladores, a entrar na construção, criando um gradiente de pressão de fora para dentro da instalação. Esse sistema é o mais comum nos aviários de construção aberta, podendo ser de dois tipos: em modos túnel e lateral.

Mesmo assim, ainda tem sido um grande desafio a criação de frangos, principalmente em climas quentes, e por isso, tem surgido à possibilidade de criação de frangos de corte em aviários com sistema dark house, visando 
ROVARIS, E. et al. Desempenho de frangos de corte criados em aviários dark house versus convencional. PUBVET, Londrina, V. 8, N. 18, Ed. 267, Art. 1778, Setembro, 2014.

melhorias no desempenho dos lotes. Este sistema, já tem sido utilizado há muito tempo em galpões de matrizes, e em outros países também para aves de corte, obtendo-se bons resultados. Dados de desempenho de frangos criados nos Estados Unidos, descritos por Gallo (2009) demonstraram redução na conversão alimentar de 50 a 90 gramas, maior ganho de peso, redução na idade de abate de 3 a 5 dias e redução de 1 a $2 \%$ na mortalidade total do lote.

Assim o objetivo deste estudo foi avaliar em qual sistema de criação (aviários convencionais com ventiladores e nebulizadores ou dark house) obtêm-se melhores resultados zootécnicos na criação de frangos de corte, criados em clima quente.

\section{Material e Métodos}

O experimento foi conduzido em aviários de uma empresa integradora, localizados no médio norte de Mato Grosso, sendo que a média de temperatura anual é $24^{\circ} \mathrm{C}$ e as máximas chegam a $38^{\circ} \mathrm{C}$.

Os frangos (machos) da linhagem comercial Cobb foram distribuídos em delineamento inteiramente casualizado.

Os tratamentos consistiram em dois diferentes tipos de galpões de 1500 $\mathrm{m}^{2}$ cada. Tratamento 1: galpão com sistema convencional, os quais possuíam 24 ventiladores dispostos no modo túnel, com telhado de alozinco, forração, chão batido, nebulização, arborização e lonas amarelas, nos quais foram alojados 10,8 aves por $\mathrm{m}^{2}$. Tratamento 2: galpão com sistema dark house, os quais possuíam 7 exaustores, telhado isotérmico, lonas pretas na parte interna e prateada na parte externa, chão batido, pad colling cerâmico associado com nebulização, nos quais foram alojados 13 aves por $\mathrm{m}^{2}$. 0 material utilizado para a cama em ambos os tratamentos foi palha de arroz.

Foram avaliados 24 lotes no sistema dark house e 56 lotes no sistema convencional. As aves utilizadas eram de mesma procedência, provenientes do mesmo incubatório.A ração foi fornecida a vontade em comedouros 
ROVARIS, E. et al. Desempenho de frangos de corte criados em aviários dark house versus convencional. PUBVET, Londrina, V. 8, N. 18, Ed. 267, Art. 1778, Setembro, 2014.

automáticos e os bebedouros tipo nipple.Os dados foram coletados no período de agosto de 2011 a agosto de 2012.

Os aviários dark house possuíam iluminação artificial, sendo que a intensidade de luz foi de 20lux na primeira semana, reduzindo para 10lux na segunda semana até os 42 dias de idade.

O desempenho foi avaliado através das variáveis peso corporal, ganho de peso, consumo alimentar, conversão alimentar, mortalidade e índice de calos de patas. Em cada lote foi pesado $100 \%$ das aves, de forma a obter o peso corporal e o ganho de peso.

O consumo foi obtido pela diferença entre a ração fornecida e a sobra, e a conversão alimentar calculada pela relação do consumo total de ração pelo ganho de peso. A mortalidade foi calculada pela diferença entre o número de pintinhos alojados e o número de frangos mortos até o carregamento, o índice de calos de patas foi avaliado visualmente por amostragem de $5 \%$ de cada lote abatido, e classificado somente em duas categorias com e sem calo de pata. Cada lote foi considerado uma repetição.

Os dados foram submetidos à análise de variância e para diferença entre médias utilizou-se o teste de Fisher, ao nível de $5 \%$ de probabilidade. Utilizouse para a análise o pacote estatístico SAEG (2008).

\section{Resultados e Discussão}

Os dados de peso corporal aos 42 dias, ganho de peso, consumo de ração, conversão alimentar, mortalidade e índice de calo de pata estão apresentados na tabela 01.

Houve efeito significativo $(P<0,05)$ para as variáveis peso corporal aos 42 dias de idade (PC), ganho de peso (GP), consumo de ração (CR), conversão alimentar (CA), calo de pata (ICP), de forma que as aves que foram criadas nos galpões dark house apresentaram melhores PC, GP e CA. Estes resultados demonstram que o sistema dark house proporcionou aos frangos um ambiente com melhor conforto. Resultados semelhantes também foram encontrados por 
ROVARIS, E. et al. Desempenho de frangos de corte criados em aviários dark house versus convencional. PUBVET, Londrina, V. 8, N. 18, Ed. 267, Art. 1778, Setembro, 2014.

Bueno e Rossi (2006) que avaliaram lotes da linhagem Ross por 14 meses em dois tipos de galpões (com ventiladores e nebulizadores $x$ exaustores $e$ nebulizadores), sendo que nenhum deles era em sistema dark house, porém com tecnologia similar e os autores concluíram que o desempenho das aves foi melhor, no galpão com exaustores provavelmente em função de melhores condições de conforto térmico, proporcionado pelos exaustores e nebulizadores.

Tabela 1. Médias de peso corporal aos 42 dias de idade (PC), ganho de peso $(G P)$, consumo de ração (CR), conversão alimentar (CA), mortalidade (MORT) e incidência de calo (ICP) de pata em frangos de corte, de acordo com os diferentes tratamentos.

\begin{tabular}{ccccccc}
\hline Tratamentos & $\mathbf{P C}$ & $\mathbf{G P}$ & $\mathbf{C R}$ & $\mathbf{C A}$ & MORT & ICP \\
& $\mathbf{( k g )}$ & $\mathbf{( k g )}$ & $\mathbf{( k g )}$ & $\mathbf{( k g / k g )}$ & $\mathbf{( \% )}$ & $\mathbf{( \% )}$ \\
\hline Aviário convencional & $2,72 \mathrm{~b}$ & $2,67 \mathrm{~b}$ & $5,16 \mathrm{~b}$ & $1,78 \mathrm{~b}$ & $2,98 \mathrm{a}$ & $22,8 \mathrm{a}$ \\
Aviário dark house & $2,96 \mathrm{a}$ & $2,92 \mathrm{a}$ & $4,96 \mathrm{a}$ & $1,73 \mathrm{a}$ & $3,58 \mathrm{a}$ & $36,9 \mathrm{~b}$ \\
\hline $\mathrm{CV}$ & 3,53 & 3,46 & 7.46 & 3,19 & 35,90 & 76,09 \\
\hline
\end{tabular}

Médias seguidas de mesma letra, na coluna não diferem estatisticamente pelo teste de Fisher, ao nível de 5\% de probabilidade

Conforme Gallo (2009); Verdi (2009) o sistema dark house permite conduzir lotes com luminosidade controlada, mantendo as aves mais calmas, reduzindo lesões na carcaça e consequentemente à dermatite e também permite alojar uma densidade de aves por $\mathrm{m}^{2}$ maior que em outros aviários.

Não foi observado diferenças significativas na taxa de mortalidade, talvez em função do bom manejo que foi adotado em todos os lotes. Nowickiet al.(2012) trabalhando com frangos de corte das linhagens Cobb e Ross criados em aviários convencionais e dark também não encontraram diferenças significativas na taxa de mortalidade e no ganho de peso dos lotes.

Comparando o desempenho de lotes de frangos de corte, criados em 3 sistemas, convencional (que possui ventilação positiva com ventiladores), túnel 
ROVARIS, E. et al. Desempenho de frangos de corte criados em aviários dark house versus convencional. PUBVET, Londrina, V. 8, N. 18, Ed. 267, Art. 1778, Setembro, 2014.

(que possui ventilação negativa com exaustores) e dark house (que possui ventilação negativa com exaustores e controladores de luminosidade), sendo que todos possuem nebulizadores, Verdi (2009) verificou que o peso corporal e o ganho de peso foram melhores no sistema dark, entretanto não encontraram diferenças para taxa de mortalidade.

Avaliando o desempenho de frangos criados em três tipos diferentes de galpões (convencionais, blue house e dark house) no estado de São Paulo, Bichara (2009) observou melhor resultado de conversão alimentar no sistema dark house, mas o ganho de peso diário não foi diferente nos três sistemas.

Rovaris et al. (2012) analisando dados de uma empresa situada em região quente em período com média de temperatura $34^{\circ} \mathrm{C}$ e $80 \%$ de umidade, obtiveram melhores índices de ganho de peso diário e conversão alimentar nos frangos de corte criados em aviários dark house em comparação aos criados em aviários convencionais.

Gallo (2009) analisou dados de uma empresa brasileira em 3 tipos de galpões convencional, ventilação negativa e dark house, este salientou que o grande ganho do último sistema consiste na menor conversão alimentar.

As diferenças de $C A, P C, \mathrm{~kg} / \mathrm{m}^{2}$, número de aves abatidas e alojadas estão apresentados na tabela 2.

Tabela 2. Diferença de $C A$, média de aves alojadas (MA), média de aves abatidas (MAB), peso corporal (PC), $\mathrm{Kg} / \mathrm{m}^{2}$

\begin{tabular}{cccrcr}
\hline Tratamentos & $\begin{array}{c}\text { CA } \\
(\mathbf{k g} / \mathbf{k g})\end{array}$ & MA & MAB & $\begin{array}{c}\text { PC } \\
\mathbf{( k g )}\end{array}$ & $\mathbf{K g} / \mathbf{m}^{\mathbf{2}}$ \\
\hline Aviário convencional & 1,78 & 16,234 & 15,559 & 2,81 & 29,15 \\
Aviário dark house & 1,73 & 19,305 & 18,495 & 3,06 & 37,72 \\
\hline Diferença & 0,05 & 3,071 & 2,936 & 0,250 & 8,57 \\
\hline
\end{tabular}

Conforme a tabela 02 percebe-se que as aves alojadas no sistema dark house consumiram $50 \mathrm{~g}$ de ração a menos em relação às aves do sistema 
ROVARIS, E. et al. Desempenho de frangos de corte criados em aviários dark house versus convencional. PUBVET, Londrina, V. 8, N. 18, Ed. 267, Art. 1778, Setembro, 2014.

convencional, cada repetição economizou $924 \mathrm{~kg}$ de ração considerando o preço médio da ração em todas as fases de produção de $R \$ 0,54$, a economia foi de $R \$ 499,00$.

O objetivo da produção de frangos é produzir quilograma de carne e quanto maior a produção por $\mathrm{m}^{2}$ os custos de produção são diluídos, o sistema dark house mostrou-se mais eficiente em relação ao convencional, pois produziu $8,57 \mathrm{~kg} / \mathrm{m}^{2}$ a mais. Isto se deve ao melhor desempenho dos frangos aliado a maior densidade que este sistema permite alojar.

Outro aspecto a considerar, quando se compara os dois tipos de sistemas (convencional e dark house), é o que foi relatado por Owada, et al. (2007) avaliando o comportamento das aves em relação à luminosidade afirmam que este é um dos pontos mais importantes na criação de frangos de corte, pois estes observaram em experimentos realizados por eles que o excesso de iluminação (maior que 10 lux) não leva a qualquer benefício adicional e podem prejudicar a produção favorecendo comportamentos de agressividade, hiperatividade e canibalismo.

Observou-se diferenças significativas na incidência de calos de pata nos frangos, de forma que as aves criadas em galpões com sistema dark house apresentaram maiores incidências de calos. Isto pode ter ocorrido em função da maior densidade (aves/ $\mathrm{m}^{2}$ ) do sistema dark house. Ou seja, no sistema convencional a umidade é mais facilmente retirada da instalação através do manejo das cortinas laterais dos aviários, enquanto que no sistema dark house não são manejadas as cortinas laterais, já que neste sistema do alojamento até o abate das aves, o galpão fica totalmente fechado, conseqüentemente é mais difícil à retirada da umidade do ambiente, ocasionando uma cama mais úmida e mais propensa à formação de calos de patas nas aves.

Estes resultados estão de acordo com Muniz et al. (2006) que avaliaram a incidência de calos de pata no abate de frangos em três diferentes densidades (10, 15 e 20 aves $/ \mathrm{m}^{2}$ ) e obtiveram diferenças significativas entre as três densidades, sendo que conforme a densidade foi aumentada também aumentou o percentual de calo de patas. 
ROVARIS, E. et al. Desempenho de frangos de corte criados em aviários dark house versus convencional. PUBVET, Londrina, V. 8, N. 18, Ed. 267, Art. 1778, Setembro, 2014.

Cabe ressaltar que os calos de patas passaram a ter maior relevância nos últimos anos devido ao direcionamento dos pés de frangos para os mercados da Ásia, portanto o rendimento percentual de patas passou a ser um fator econômico importante (VIEIRA, 2009), portanto, é importante o manejo adequado para redução deste índice.

Em trabalho realizado por Deep et al. (2010) no qual correlacionaram a intensidade de luz com a porcentagem de calos de pata avaliando 4 intensidades de luz $(1,10,20$ e 40 lux $)$ em frangos de corte da linhagem Ross, dos 7 aos 35 dias de idade, verificaram que não houve diferença de peso corporal, consumo de ração, conversão alimentar e mortalidade, porém na intensidade de 1 lux foi observado lesões ulcerativas no coxim plantar. Blatchford et al. (2009) descrevem que o aumento da incidência de lesões ulcerativas coxins plantares, o calo de pata, com a diminuição da intensidade da luz deve-se provavelmente à maior duração do tempo de repouso, o que resulta em um tempo de contacto maior entre o pé e a cama.

Bessei (2006) citado por Owada et al. (2007) revisando pontos críticos de bem-estar na produção de frangos de corte, apontou como importante o controle do regime e da intensidade de luz em aviários, pois a intensidade da luz pode influenciar diretamente na atividade motora e possível exaustão das aves levando aparecimento de anormalidades locomotoras.

Porém os resultados de Carvalho et al.(2011) os quais avaliaram 4 tipos de aviários (dois tipos de Blue house, dark house e convencional) em relação à eficiência de ventilação e qualidade do ar, verificaram uma maior homogeneidade no aviário dark house, ou seja, uma melhor qualidade de cama em relação aos outros que obtiveram pontos com altos valores de umidade, os mesmos atribuíram que o galpão dark house possui maior controle das variáveis climáticas por apresentar maior isolamento térmico. 
ROVARIS, E. et al. Desempenho de frangos de corte criados em aviários dark house versus convencional. PUBVET, Londrina, V. 8, N. 18, Ed. 267, Art. 1778, Setembro, 2014.

\section{Conclusões}

O sistema dark house propiciou melhores peso corporal aos 42 dias de idade, ganho de peso, consumo e conversão alimentar para criação de frangos de corte em regiões de clima quente.

No sistema convencional apresentou menor índice de calos de patas.

\section{Referências Bibliográficas}

BLATCHFORD, R. A.; KLASING, K. C.; SHIVAPRASAD, H. L.The effect of light intensity on the behavior, eye and leg health, and immune function of broiler chickens. Poultry Science, $v$. 88, n.1, p. $20-28,2009$.

BUENO, L.; ROSSI, A.L. Comparação entre tecnologias de climatização para criação de frangos quanto à energia, ambiência e produtividade. Revista Brasileira de Engenharia Agrícola e Ambiental, v.10, n. 2, p.497-540, 2006.

BICHARA, T. Aviário azul e dark-house para frangos de corte -Desenvolvendo novos conceitos para aviários pressão negativa. X Simpósio Brasil Sul de Avicultura e I Brasil Sul Poultry Fair. Chapecó, 2009.

CARVALHO, T. M. R.; MOURA, D. J.; SOUZA, Z. M.; SOUZA, BUENO, G. S.; L. G. F. Qualidade da cama e do ar em diferentes condições de alojamento de frangos de corte. Pesq.agropec. bras., v.46, n.4, p.351-361, 2011.

DEEP, A.; SCHWEAN-LARDNER, K.; CROWE, T. G. I.Impact of light intensity on broiler biological rhythms and welfare.Poultry. Science, v.89, n.11 p.2326-2333, 2010.

GALLO, B. B. Dark house: manejo x desempenho frente ao Sistema tradicional. X Simpósio Brasil Sul de Avicultura e I Brasil Sul Poultry Fair. Chapecó, 2009.

MUNIZ, C. E. Influência da densidade populacional sobre o peso médio, percentual de calos de patas e histoforfometria da bolsa cloacal das aves (Gallus gallus). 2006 . 34 p. Dissertação (conclusão de mestrado) Universidade Federal de Mato Grosso do Sul, Campo Grande.

NAZARENO, A C.; PANDORFI, H.; GLEDSON, L. P.; GIONGO, R. P.; PEDROSA, R. M. E.; GUISELINI, C. Avaliação do conforto térmico e desempenho de frangos de corte sob regime de criação diferenciado. Revista Brasileira de Engenharia Agrícola e Ambiental, v. 13, n.6, p. $802-808,2009$.

NOWICKI, R.; BUTZGE, E.; OTUTUMI, L. K.; PIAU-JÚNIOR, R.; ALBERTON, L. R.; MERLINI, L. S.; MENDES, T. C.; DALBERTO, J. L.; GERÔNimo, E.; CAETANO, I. C. S. Desempenho de frangos de corte criados em aviários convencionais e escuros. Arq. Ciênc. Vet. Zool. UNIPAR, v. 14, n. 1, p. 25-28, 2011.

OWADA, N. A.; NÄÄS, A. I.; MOURA, D. D.; BARACHO, M.Estimativa de bem-estar de frango de corte em função da concentração de amônia e grau de luminosidade no galpão de produção. Engenharia Agrícola Jaboticabal, v. 27, n. 3, p.611-618, 2007. 
ROVARIS, E. ;CORRÊA, G. S. S.; CORRÊA, B. A.; LUNA, U. V. Avaliação da conversão alimentar e do ganho médio de peso diário de frangos de corte em dois sistemas de produção - dark house e convencional.XXII Congresso brasileiro de zootecnia. Cuiabá, 2012.

TINÔCO, F. F. I. A granja de frangos de corte. In: Mendes, A. Nääs, I. Macari, M. Produção de frangos de corte, $1^{a}$ ed., Campinas: FACTA, Cap. 4, p.56-82, 2004.

UNIVERSIDADE FEDERAL DE VIÇOSA. Sistema para análise estatística e genética - SAEG. Versão 9.1 Viçosa, MG:UFV 2008.

VERDI, P. Sistemas de automação em dark house para ambiência de frango de corte. Workshop Embrapa suínos e aves. 2009.

VIEIRA, S.L. Defeitos visuais - Dermatites de contato. In: Qualidade visual de carcaça de frangos de corte: uma abordagem a partir do ambiente de produção, $2^{a}$ ed., Cascavel:Gráfica Positiva, p.55-59, 2009.

WELKER, S. J.; ROSA, P. A.; MOURA, J. D.; MACHADO, P. L.; CATELAN, F. UTTPATEL, R. Temperatura corporal de frangos de corte em diferentes sistemas de climatização. Revista Brasileira de Zootecnia, v. 37, n. 8, p. 143-1467, 2008. 